\title{
Case series on obstetrical outcomes in patient with uterine malformations
}

\author{
Kirti Solanki*, Swati Kochar, Laxmi Poonia
}

Department of Obstetrics and Gynaecology, Sardar Patel Medical College, Bikaner, Rajasthan, India

Received: 14 July 2020

Revised: 07 August 2020

Accepted: 14 August 2020

\author{
*Correspondence: \\ Dr. Kirti Solanki, \\ E-mail: solanki.kirti100@gmail.com
}

Copyright: () the author(s), publisher and licensee Medip Academy. This is an open-access article distributed under the terms of the Creative Commons Attribution Non-Commercial License, which permits unrestricted non-commercial use, distribution, and reproduction in any medium, provided the original work is properly cited.

\begin{abstract}
Congenital uterine anomalies occur due to abnormal fusion of mullerian duct during embryonic life. It is associated with high incidences of reproductive failures and adverse obstetrical outcomes. It may be associated with malpresentation, preterm labour, or recurrent pregnancy losses. Authors report a case series of 7 patients which were admitted in obstetrics and gynaecology department of SP medical college and associated group of hospitals between time period of March 2019 to July 2019. Among 7 cases 6 cases were associated with malpresentation, 1 with abortion, and 1 with preterm labour. This series shows that uterine anomalies are associated with different obstetrical outcomes varying from totally uneventful antenatal and postnatal period to abortion or preterm labour. Prenatal diagnosis of uterine anomaly may help in improving the obstetrical outcome in these patients.
\end{abstract}

Keywords: Congenital uterine anomaly, Malpresentation, Preterm labour, Recurrent pregnancy loss

\section{INTRODUCTION}

Congenital uterine malformations are uterine abnormalities caused by abnormal embryologic formation, fusion or resorption of mullerian ducts which are primordial analogue of female reproductive tract. ${ }^{1}$ Its prevalence is $2-4 \%$ in reproductive age group and $5-25 \%$ in women with adverse reproductive outcomes. ${ }^{2-4}$ Mullerian duct anomaly are classified according to 1988 American fertility society classification (Figure 1). ${ }^{5}$

Uterine malformations in order of their occurrence arearcuate uterus followed by septate uterus, bicornuate uterus, didelphic uterus and unicornuate uterus. These malformations are associated with various obstetrical outcomes like first and second trimester abortions, malpresentations, fetal growth restriction, fetal demise, premature rupture of membranes, preterm delivery, increased risk of ectopic pregnancy. ${ }^{6-11}$ These outcomes are principally due to abnormal uterine blood flow, cervical incompetency, diminished cavity size or muscle mass of uterus. The objective of this study is to look for the various pregnancy outcomes in patients with uterine anomalies.

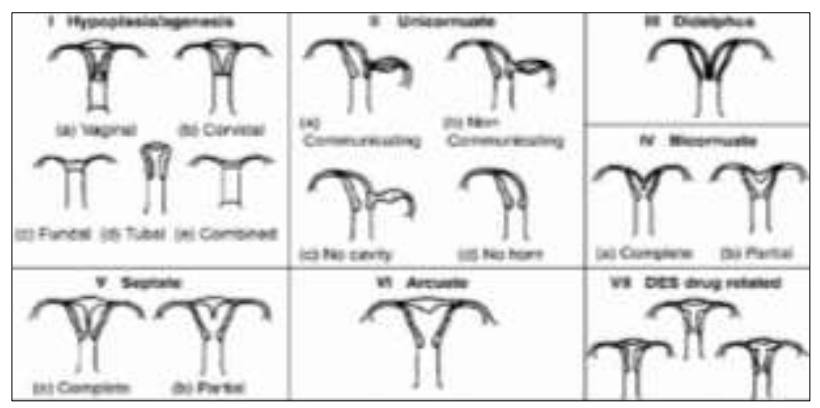

Figure 1: American fertility society classification of uterine anomlies.

This study was conducted in obstetrics and gynaecology department of Sardar Patel medical college and associated group of hospitals between time period of 
March 2019 to July 2019. Among pregnant ladies admitted during this period 7 patients were found to have uterine anomalies, which were diagnosed either by first trimester USG scan or as intraoperative finding during caesarean delivery.

\section{CASE SERIES}

\section{Case 1}

A 32 years primigravida female was admitted in labour room of PBM hospital Bikaner at 36 weeks of gestation with labour pain. Patient had conceived spontaneously. She had attended regular ANC clinics. Her antenatal period was uneventful. Her first trimester USG scan showed bicornuate uterus with 7 weeks of pregnancy in left cornu as shown in Figure 2. Her ANC investigations were in normal range. Her general physical examination was within normal limits. On per abdominal examination fundal height was consistent with 36 weeks of gestation with breech presentation. Fetal heart rate was 132 per minute. On per vaginal examination cervix was found to be $3 \mathrm{~cm}$ dilated, partly effaced with membranes present over fetal presenting part. Her USG findings showed a single live pregnancy of $35 \pm 2$ weeks in breech presentation. After explaining all fetomaternal risk decision of cesarean section was taken. On cesarean section a male child of $2.4 \mathrm{~kg}$ was born. Intraoperative findings were suggestive of bicornuate uterus. Postoperative period of patient was uneventful.

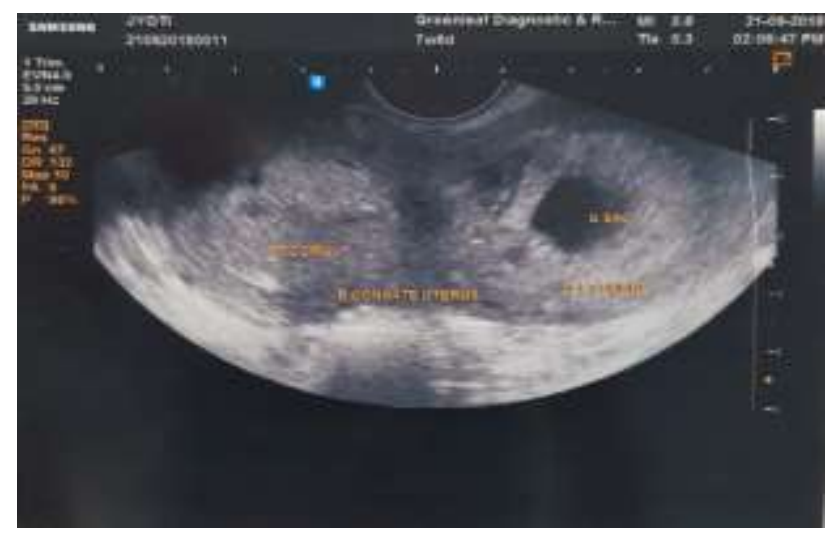

Figure 2: Ultrasound showing bicornuate uterus with 7 weeks of pregnancy in left cornu.

\section{Case 2}

A primigravida female aged 26 years presented at labour room at 39 weeks of gestation with complain of labour pain. She had attended antenatal clinic twice. Her earliest trimester scan showed bicornuate uterus with single live pregnancy of 11 weeks in right cornu of uterus. At time of admission her blood pressure was $150 / 90$, pulse was $82 /$ minute. Her per abdominal examination showed fundal height of 30-32 weeks with transverse lie of fetus, mild uterine contractions were present. Fetal heart rate was 128 per minute. Her per vaginal examination showed closed cervix with show. Her USG scan showed single live fetus of $36 \pm 2$ weeks in transverse lie with head in right flank. Her routine ANC investigations were in normal range. After explaining all fetomaternal risk and informed consent cesarean section was done in which she gave birth to male child of $3 \mathrm{~kg}$ who was extracted as breech. Intraoperative findings were consistent with patients earliest USG scan showing bicornuate uterus. Postoperative period of patient was uneventful.

\section{Case 3}

A female aged 28 years presented to emergency of obstetrics and gynecology department of PBM hospital with complain of bleeding per vaginum at 14 weeks of gestation. She was second gravida who had previous 1 spontaneous abortion at 16 weeks of gestation 3 year back. Her general physical examination was normal and patient was vitally stable. Her per vaginal examination showed presence of bleeding, uterus was approximately 10 weeks size with dilatation of cervix and product of conception is felt through cervical os. Patient had one USG scan report which showed bicornuate uterus with single pregnancy of 10 weeks in right cornu. Patient was admitted with provisional diagnosis of inevitable abortion and after informed consent evacuation was performed. Patient stood procedure well.

\section{Case 4}

A second gravida female aged 24 years was admitted in labour room of PBM hospital with complain of 34 weeks of pregnancy with leaking per vaginum. She had previous preterm cesarean delivery 2 year back which was conducted because of breech presentation. She was an unbooked patient who was referred from primary health care centre. She had not attended any antenatal clinics. There were no investigations available. Her general physical examination showed presence of pallor. On per abdominal examination uterus was found to be nonacting with 32-34 weeks of fundal height, oblique lie of the fetus, fetal heart sound 136 per minute. Her per vaginal examination showed 1 finger dilatation of cervix with presence of leaking. All routine investigation of patient was conducted. Her CBC report showed presence of anemia which was corrected by blood transfusion. Her USG scan showed single live pregnancy of $34 \pm 2$ weeks of gestation with oblique lie. Steroid coverage was given to patient for fetal lung maturity. After explaining all fetomaternal risk and taking informed consent patient was taken for cesarean section. She delivered a male child of $1.9 \mathrm{~kg}$. Intra-operatively authors found bicornuate uterus. Postoperative period of patient was uneventful.

\section{Case 5}

Primigravida female of 28-year-old admitted to labour room of PBM hospital at 38 weeks of gestation with complain of labour pain. She had attended antenatal 
clinic only once. At time of admission her per abdominal examination revealed breech presentation of fetus with fundal height of 36 weeks, uterine contractions present and fetal heart rate was 132 per minute and regular. On per vaginal examination $3 \mathrm{~cm}$ dilatation of cervix present with $40-50 \%$ effacement and membranes present on fetal presenting part. There were no investigation avilable. All routine investigations were done. Her all blood investigations were in normal range. Her USG showed single live pregnancy of $36 \pm 2$ weeks of gestation with breech presentation. After explaining all fetomaternal risk and taking informed consent cesarean section was planned. She gave birth to female child of $2.6 \mathrm{~kg}$. Her intra operative finding was of unicornuate uterus with non-communicating rudimentary left horn as shown in Figure 3.

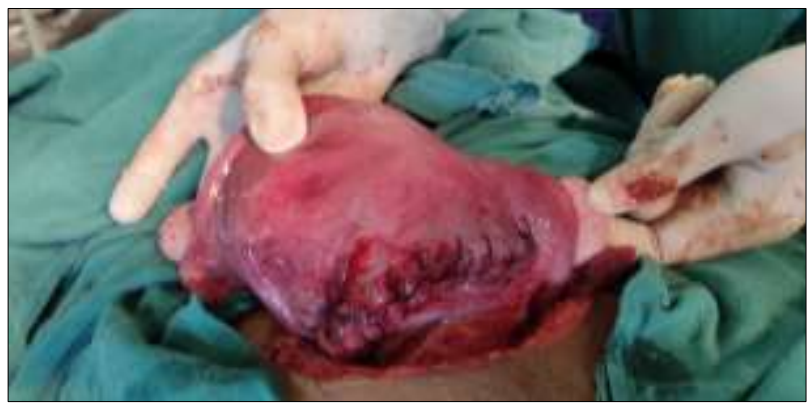

Figure 3: Caesarean delivery performed for malpresentation showing unicornuate uterus with non-communicating rudimentary left horn.

\section{Case 6}

A 32-year-old primigravida with 40 weeks of gestation presented to labour room on due date. She was a booked patient of PBM hospital antenatal clinic. She attended antenatal clinic regularly. Her all routine investigations were done which were in normal limits. Her earliest trimester scan showed bicornuate uterus with single live pregnancy of 14 weeks on left side. Her per abdominal findings were in consistent with her period of gestation. Fetus was in oblique lie. Per vaginal examination showed closed cervix. Her scan revealed single live pregnancy of 40 weeks with oblique lie. After informed consent cesarean section was planned in which she gave birth to male child of $3.75 \mathrm{~kg}$. Intraoperative findings were in consistent with that of earliest USG that showed bicornuate uterus.

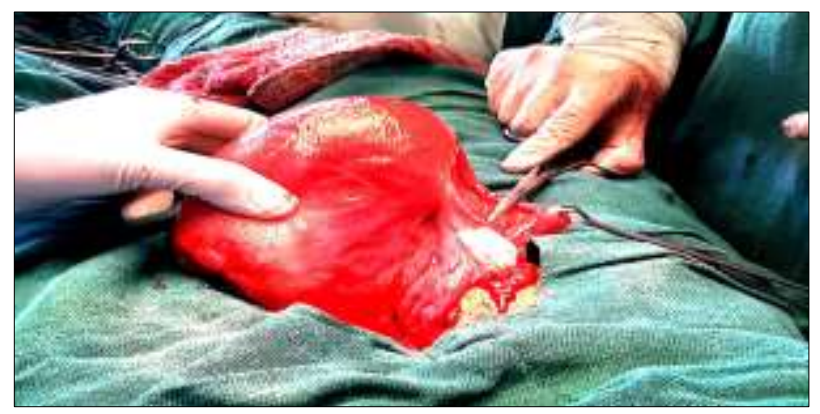

Figure 4: Caesarean section performed on a patient with history of previous 3 cesarean section, showing unicornuate uterus.

\section{Case 7}

A 35 years old female presented to antenatal clinic routine checkup. She was fourth gravida with previous 3 cesarean section. She had 35 gestational weeks pregnancy. She was a registered patient of antenatal clinic of PBM hospital who attended the clinic twice. There were no early trimester scan present. Her routine investigations were normal. Her recent USG scan showed single live pregnancy of $34 \pm 2$ weeks of gestation with cephalic presentation. After explaining all fetomaternal risk patient was admitted to labour room for preparation of cesarean section. After steroid coverage and performing all routine investigations, cesarean section was performed and a female child of $2.54 \mathrm{~kg}$ was born. Intraoperatively unicornuate uterus was found as shown in Figure 4. Her post-operative period was uneventful.

Table 1: Results.

\begin{tabular}{|c|c|c|c|c|c|c|c|}
\hline Cases & $\begin{array}{l}\text { Uterine } \\
\text { malformations }\end{array}$ & Gravid & $\begin{array}{l}\text { Period of } \\
\text { gestation }\end{array}$ & $\begin{array}{l}\text { Diagnosed } \\
\text { by }\end{array}$ & $\begin{array}{l}\text { Obstetrical } \\
\text { outcome }\end{array}$ & Presentation & $\begin{array}{l}\text { Baby } \\
\text { weight }\end{array}$ \\
\hline 1 & Bicornuate & G1 & 36 weeks & USG & LSCS & Breech & $2.4 \mathrm{~kg}$ \\
\hline 2 & Bicornuate & G1 & 39 weeks & USG & LSCS & Transverse & $3.0 \mathrm{~kg}$ \\
\hline 3 & Bicornuate & G2 & 14 weeks & USG & Abortion & - & - \\
\hline 4 & Bicornuate & G2 & 34 weeks & LSCS & LSCS & Oblique & $1.9 \mathrm{~kg}$ \\
\hline 5 & Unicornuate & G1 & 38 weeks & LSCS & LSCS & Breech & $2.6 \mathrm{~kg}$ \\
\hline 6 & Bicornuate & G1 & 40 weeks & USG & LSCS & Oblique & $3.75 \mathrm{~kg}$ \\
\hline 7 & Unicornuate & G4 & 35 weeks & LSCS & LSCS & Cephalic & $2.54 \mathrm{~kg}$ \\
\hline
\end{tabular}

\section{DISCUSSION}

In this study, authors found that patients with uterine anomalies are at increased risk of adverse pregnancy outcomes. Outcome can range from early trimester pregnancy losses to preterm labour, malpresentation or pregnancy can reach up to term without any complication. In this study authors found that out of 7 
cases 1 case was associated with second trimester abortion and 6 cases carried pregnancy till third trimester and undergone cesarean section. Among 6 cases on which cesarean section was performed 5 cases were associated with malpresentation, among which 2 were in breech position, 2 in oblique lie and 1 in transverse lie. Also, among 7 cases 1 case was associated with preterm labour. Many studies were conducted which have shown that patients with uterine anomalies have an increased risk of these outcomes data. One meta-analysis by Chan et al combined patient from multiple prior studies and reported risks of adverse outcomes based on the specific type of uterine anomaly. ${ }^{6}$ However, they only studied third trimester pregnancy outcomes like preterm labor and malpresentation at delivery. They did not report cesarean rates. Another study by Hua et al compared outcomes in 203 patients with uterine anomalies to 66 753 unexposed patients. ${ }^{11}$ Hua et al found that uterine anomaly was associated with preterm birth, cesarean delivery and IUGR (defined as a birth weight less than the $10^{\text {th }}$ percentile). Another novel finding in their study was the increased risk of caesarean delivery seen in patients with uterine anomalies, even in patients who attempted vaginal delivery. It is well known that uterine anomalies increase the risk of malpresentation, which could partially explain an overall increased risk of cesarean delivery. However, even in patients who labored and attempted vaginal delivery, there was a statistical trend toward an increased risk of cesarean delivery in patients based on the severity of uterine abnormality. Therefore, not only does a uterine anomaly increase the risk of cesarean delivery from causes such as malpresentation and placenta previa, it may also increase the risk of cesarean delivery in labor as well and more research is warranted as this is important information when counseling patients with these abnormalities. Uterine malformations can be diagnosed by USG or it can be an incidental finding during operative procedure. In the above case series authors found that out 7 cases 4 cases were diagnosed by earliest scan and 3 cases were diagnosed during operative procedure. It is also known that uterine malformations are associated with various obstetrical outcomes.

\section{CONCLUSION}

In present case series authors observed that uterine malformations are associated with abortions, malpresentations or preterm labour. Hence it can be concluded that uterine anomalies can be a predisposing factor for these obstetrical outcomes. Hence by early diagnosis of uterine malformations authors can reduce obstetrical complications and can improve outcome.
Funding: No funding sources

Conflict of interest: None declared

Ethical approval: Not required

\section{REFERENCES}

1. Ribeiro SC, Tormena RA, Peterson TV, Gonzáles MD, Serrano PG, Almeida JA, et al. Müllerian duct anomalies: review of current management. Sao Paulo Med J Rev Paul Med. 2009;127(2):92e96.

2. Grimbizis GF, Camus M, Tarlatzis BC, Bontis JN, Devroey P. Clinical implications of uterine malformations and hysteroscopic treatment results. Hum Reprod Update. 2001;7:161-74.

3. Chan YY, Jayaprakasan K, Zamora J, Thornton JG, Raine-Fenning N, Coomarasamy A, et al. The prevalence of congenital uterine anomalies in unselected and high-risk populations: a systematic review. Hum Reprod Update. 2011;17:761-71.

4. Acien P. Incidence of mu" llerian defects in fertile and infertile women. Hum Reprod. 1997;12:1372-6.

5. The American Fertility Society classifications of adnexal adhesions, distal tubal occlusion, tubal occlusion secondary to tubal ligation, tubal pregnancies, mullerian anomalies and intrauterine adhesions. Fertil Steril. 1988;49:944-55.

6. Chan YY, Jayaprakasan K, Tan A, Thornton JG, Coomarasamy A, Raine-Fenning NJ. Reproductive outcomes in women with congenital uterine anomalies: a systematic review. Ultrasound Obstet Gynecol. 2011;38:371-82.

7. Reichman D, Laufer MR, Robinson BK. Pregnancy outcomes in unicornuate uteri: a review. Fertil Steril. 2009;91:1886-94.

8. Ludmir J, Samuels P, Brooks S, Mennuti MT. Pregnancy outcome of patients with uncorrected uterine anomalies managed in a highrisk obstetric setting. Obstet Gynecol. 1990;75:906-10.

9. Grimbizis GF, Camus M, Tarlatzis BC, Bontis JN, Devroey P. Clinical implications of uterine malformations and hysteroscopic treatment results. Hum Reprod Update. 2001;7:161-74.

10. Andrews $M$, Jones $H$. Impaired reproductive performance of the unicornuate uterus: intrauterine growth retardation, infertility and recurrent abortion in five cases. Am J Obstet Gynecol. 1982;144:173-6.

11. Hua M, Odibo AO, Longman RE, Macones GA, Roehl KA, Cahill AG. Congenital uterine anomalies and adverse pregnancy outcomes. Am J Obstet Gynecol. 2011;205:558.e1-5.

Cite this article as: Solanki K, Kochar S, Poonia L. Case series on obstetrical outcomes in patient with uterine malformations. Int J Reprod Contracept Obstet Gynecol 2020;9:3862-5. 